\title{
Use of vaginal misoprostol before endometrial biopsy in premenopausal women: an observational study
}

\author{
Prabhavathi V. ${ }^{1}$, Prasad D. K. V. ${ }^{2}$, Lahari N. ${ }^{1}$, Satyavathi R. ${ }^{1 *}$
}

\begin{abstract}
${ }^{1}$ Department of Obstetrics and Gynecology, NRI Institute of Medical Sciences, Sangivalasa, Visakhapatnam, India
${ }^{2}$ Department of Biochemistry, NRI Institute of Medical Sciences, Sangivalasa, Visakhapatnam, India
\end{abstract}

Received: 12 March 2020

Accepted: 07 April 2020

*Correspondence:

Dr. Satyavathi R.,

E-mail: ramadindisatya@gmail.com

Copyright: (c) the author(s), publisher and licensee Medip Academy. This is an open-access article distributed under the terms of the Creative Commons Attribution Non-Commercial License, which permits unrestricted non-commercial use, distribution, and reproduction in any medium, provided the original work is properly cited.

\begin{abstract}
Background: It is well-known since long time the beneficial effects of misoprostol particularly as a cervical softening agent in obstetric practice. Keep in view, study aimed to evaluate the efficacy of vaginal misoprostol 400 mcg before endometrial biopsy in premenopausal women.

Methods: All the 200 patients were classified into two groups viz. study group (Group I) with 100 patients and control group (Group II) with 100 patients. To Group I patients, $400 \mathrm{mcg}$ of misoprostol was given vaginally, 4 hours prior to the commencement of endometrial biopsy whereas no medication was received by Group II patients.

Results: In the present study, the base line cervical dilatation is found to be $5.8 \pm 1.3 \mathrm{~mm}$ in Group I patients whereas $3.8 \pm 0.92 \mathrm{~mm}$ in Group II patients which is significantly higher $(\mathrm{p}<0.05)$. Only 32 patients in Group I required further dilatation whereas 88 patients in Group II underwent further dilatation. The mean time required for further dilatation in Group I and Group II patients was $42.6 \pm 17.4,64.6 \pm 16.8 \mathrm{sec}$ respectively and was significantly higher in Group II patients $(\mathrm{p}<0.05)$. Out of 100 patients in Group I, only $2 \%$ of patients complained severe pain whereas in Group II $48 \%$ of patients experienced intolerable pain and required anesthesia.

Conclusions: Vaginal administration of $400 \mathrm{mcg}$ misoprostol 4 hours prior to endometrial biopsy in premenopausal women had a significant effect on cervical resistance and cervical dilatation.
\end{abstract}

Keywords: Cervical injury, Cervical ripening, Endometrial biopsy, Prostaglandin E1, Visual analog scale score

\section{INTRODUCTION}

Endometrial biopsy is a routine day care procedure used to assess the abnormal uterine bleeding, postmenopausal bleeding, recurrent pregnancy loss, infertility., Sometimes, it is very difficult to pass the endometrial curette through the cervix into the uterine cavity. In addition, the complications such as cramping pain, vasovagal reaction, bleeding and cervical/ uterine injuries are commonly encountered during the procedure.

Misoprostol, a prostaglandin E1 analogue has been found to be effective in cervical ripening/softening agent in obstetric practice. $^{3-6}$ The same effectiveness of misoprostol has been observed in gynaecological procedures such as hysteroscopy, endometrial biopsy to soften the cervix and also to treat submucosal fibroids, polyps etc. Misoprostol can be administered oral, vaginal and sublingual routes and the ideal recommended dose is 400 mcg 3-4 hours prior to gynaecological procedures such as endometrial biopsy, hysteroscopy and fractional curettage. The sublingual route is more effective than oral and vaginal routes of administration, but with more side effects. ${ }^{7}$ Similarly, vaginal administration has been found to be more effective than oral route with fewer side effects. ${ }^{8-10}$ The peak plasma misoprostol concentration is reached in 1-2 hours following vaginal application. The side effects such as nausea, vomiting, diarrhoea, 
abdominal cramps, fever etc are the most common and are dose dependent. However, these side effects can be reduced by administration of drug vaginally rather than oral route. ${ }^{11,12}$ Although the beneficial effects of misoprostol have been successfully studied in obstetrics, the studies related beneficial effects in gynaecological operations are lacking. Hence, the present study was aimed to evaluate the efficacy of vaginal misoprostol 400 mcg administration before endometrial biopsy in nonpregnant, premenopausal women.

\section{METHODS}

This study was conducted in out-patient department of obstetrics and gynecology in NRI Institute of Medical Sciences, a tertiary care teaching hospital during May 2019 and October 2019. Two hundred non-pregnant premenopausal women between the age group of 30-50 years with abnormal uterine bleeding were included in the study after taking written informed consent. The pregnant and post-menopausal women, patients with a H/o bronchial asthma, abnormal liver function tests, medical disorders were excluded from the study. The study was approved by the Institutional Ethics Committee, NRIIMS.

By using computer generated randomization protocol, all the recruited patients with abnormal uterine bleeding were classified into two groups: study group (Group I) with 100 patients, and control group (Group II) with 100 patients. To Group I patients $400 \mathrm{mcg}$ of misoprostol was given vaginally, 4 hours prior to the commencement of endometrial biopsy whereas no medication was received by Group II patients. Before sending the patients to operation theatre, vaginal wash with normal saline was given to all the patients particularly to Group I patients to remove any traces of the drug. The operative procedure was initiated without using any analgesics and anesthesia.
Using the large size (no. 8) Hegar's dilator, the primary outcome measure was assessed whether that could be inserted without resistance at the beginning of the procedure. The secondary outcomes such as;

- Need for further dilatation

- Ease of dilatation

- Anesthesia/ analgesia usage

- Cervical consistency

- Pain assessment by VAS score

were also studied in all the patients of Group I and Group II. The subjective assessment of pain during the procedure was divided into four groups viz. no discomfort (0), mild discomfort (1-2), mild to moderate pain (3-4) and moderate to severe pain (5 and >5). The patients who have experienced moderate to severe pain (VAS 5 or more) were given either analgesia or anaesthesia to continue the procedure. The side effects of misoprostol such as nausea, vomiting, diarrhea, abdominal pain, cramps, vaginal spotting, vaginal bleeding, shivering and pyrexia of significance were recorded. Pre-operative complications like cervical injury, uterine perforation was also noted.

\section{Statistical analysis}

Data were analysed using OpenEpi 2.3. Primary and secondary outcome between both the groups were compared by chi-square and t-test analysis and p-value $<0.05$ was considered statistically significant.

\section{RESULTS}

The demographic features such as age, parity and body mass index (BMI) were depicted in Table 1. The primary and secondary outcomes of misoprostol administration were presented in Table 2.

Table 1: Demographics of patients.

\begin{tabular}{|lllll|}
\hline Characteristics & Study group (Group I) & Control group (Group II) & Chi-square & p-value \\
\hline Age in years (mean \pm SD) & $37.9 \pm 6.65$ & $39.3 \pm 5.67$ & 2.49 & 0.11 \\
\hline BMI (Mean \pm SD) & $23.1 \pm 1.42$ & $22.9 \pm 1.67$ & 2.58 & 0.36 \\
\hline Parity & & & \\
\hline Nulliparous, $\mathrm{n}(\%)$ & $34(34 \%)$ & $38(38 \%)$ & 0.35 & 0.5 \\
\hline Parous, $\mathrm{n}(\%)$ & $66(66 \%)$ & $62(62 \%)$ & 0.34 & 0.5 \\
\hline
\end{tabular}

Note: ${ }^{*} \mathrm{p}<0.05$ is significant.

The mean cervical dilatation is found to be $5.8 \pm 1.3 \mathrm{~mm}$ in Group I patients whereas $3.8 \pm 0.92 \mathrm{~mm}$ in Group II patients which is significantly higher $(p<0.05)$. Out of 100 patients of Group I, 32 patients required further dilatation whereas 88 patients in Group II underwent further dilatation. The time required for cervical dilatation was very short in Group I patients whereas significantly prolonged in Group II patients $(\mathrm{p}<0.05)$ as compared to Group I. In Group II, $56.8 \%$ of patients experienced significant resistance for dilatation but only $6.3 \%$ of patients in Group I. The side-effects of misoprostol were not significant in Group I patients as compared to Group II patients although very few patients complained side effects such as nausea, diarrhoea, cramping and vaginal spotting (Table 3 ). The subjective assessment of pain during cervical dilatation was done using VAS score. Out of 100 patients in Group I, only $2 \%$ of patients complained severe pain whereas in Group 
Table 2: Effectiveness of misoprostol before commencement of procedure.

\begin{tabular}{|lllll|}
\hline Results & Group I & Group II & Chi-square & p-value \\
\hline Base line cervical dilatation Mean \pm SD $(\mathrm{mm})$ & $5.8 \pm 1.3$ & $3.8 \pm 0.92$ & 11.54 & $<0.001^{*}$ \\
\hline Further dilatation required & $32 / 100(32 \%)$ & $88 / 100(88 \%)$ & 65.01 & $<0.001^{*}$ \\
\hline Mean time for further dilatation Mean \pm SD $(\mathrm{Sec})$ & $42.6 \pm 12.1$ & $67.9 \pm 16.9$ & 10.79 & $0.001^{*}$ \\
\hline Ease of dilatation & & & \\
\hline Easy, $\mathrm{n}(\%)$ & $25 / 32(78.1 \%)$ & $10 / 88(31.8 \%)$ & 50.2 & $<0.001^{*}$ \\
\hline Mild to moderate resistance, $\mathrm{n}(\%)$ & $5 / 32(15.6 \%)$ & $28 / 88(31.8 \%)$ & 3.06 & $0.04^{*}$ \\
\hline Significant resistance, $\mathrm{n}(\%)$ & $2 / 32(6.3 \%)$ & $50 / 88(56.8 \%)$ & 24.23 & $<0.001^{*}$ \\
\hline
\end{tabular}

Note: *p-value $<0.05$ is significant.

Table 3: Side effects of misoprostol.

\begin{tabular}{|lllll|}
\hline Side effect & Group I & Group II & Chi-square & p-value \\
\hline No side effects & $82 / 100$ & $84 / 100$ & 0.14 & 0.35 \\
\hline Nausea & 3 & 1 & 0.85 & 0.17 \\
\hline Vomiting & 0 & 0 & - & - \\
\hline Diarrhoea & 3 & 0 & 2.83 & $0.04^{*}$ \\
\hline Cramping & 3 & 2 & 0.11 & 0.36 \\
\hline Abdominal pain & 4 & 5 & 0.34 & 0.27 \\
\hline Vaginal spotting & 4 & 7 & 1.74 & 0.09 \\
\hline Vaginal bleeding & 0 & 1 & 1.12 & 0.14 \\
\hline Shivering & 1 & 0 & - & - \\
\hline Fever & 0 & 0 & - & - \\
\hline No complications & $100 / 100$ & $91 / 100$ & - & - \\
\hline Cervical injury & 0 & $7 / 100$ & 9.15 & $0.001^{*}$ \\
\hline Uterine perforation & 0 & $2 / 100$ & 2.14 & 0.06 \\
\hline
\end{tabular}

Note: $* p<0.05$ is significant.

Table 4: Subjective assessment of pain during dilatation.

\begin{tabular}{|lllll|}
\hline Pain (VAS score) & Group I & Group II & Chi square & p-value \\
\hline No discomfort (0) & $38(38 \%)$ & $0(0 \%)$ & 46.68 & $<0.001^{*}$ \\
\hline Mild discomfort (1-2) & $52(52 \%)$ & $12(12 \%)$ & 36.58 & $<0.001^{*}$ \\
\hline Mild pain (3-4) & $8(8 \%)$ & $40(40 \%)$ & 27.93 & $<0.001^{*}$ \\
\hline $\begin{array}{l}\text { Moderate to severe pain required } \\
\text { analgesia/ anaesthesia (5 or more) }\end{array}$ & $2(2 \%)$ & $48(48 \%)$ & 56.14 & $<0.001^{*}$ \\
\hline
\end{tabular}

Note: VAS: visual analogue scale; ${ }^{*} \mathrm{p}<0.05$ is significant.

\section{DISCUSSION}

Misoprostol is a synthetic prostaglandin E1 analogue most commonly used for cervical priming and pain reduction before gynecological procedures because of its low cost and scientific evidence. The use of misoprostol before the endometrial biopsy helps in the cervical dilatation and thereby minimizes the cervical trauma. Misoprostol has been found to be useful particularly in premenopausal women for cervical ripening before gynecological procedures such as hysteroscopy, endometrial biopsy etc. to reduce the need for further dilatation and to minimize the rate of cervical lacerations. ${ }^{13}$ However, the usage and benefits of misoprostol in postmenopausal women is not yet clear despite very few studies have suggested an improvement in cervical dilatation. ${ }^{13,14}$

In the present study, the misoprostol received women had significantly increased base line cervical dilatation and time required for cervical dilatation was less as compared to Group II patients who did not receive any drug. In fact, the role of misoprostol has been studied in different dose format from 100 to $1000 \mathrm{mcg}$ and routes of administration such as oral, vaginal, sublingual and duration of insertion of drug before the procedure (2 hours to 12 hours). However, no studies focussed on a clear dosing regimen for cervical priming in endometrial biopsy. In the present study, a single dose of $400 \mathrm{mcg}$ given 4 hours before the start of procedure was adopted, 
and it is found to be effective with minimal side effects such as nausea, vomiting, abdominal cramping pain, diarrhea and vaginal bleeding. However, Lee et al. did not find any significant difference between oral, vaginal and sublingual application of misoprostol in such cases. ${ }^{15}$

In the present study, $400 \mathrm{mcg}$ single dose of misoprostol vaginally was given as a priming agent 4 hours prior to the procedure in premenopausal women and found to have promising results with the usage. However, Dam et al, and Perrone et al, did not find any promising effect in pre-menopausal women, rather it has caused more pain and uterine cramping. ${ }^{16,17}$ Similarly in another study, post-menopausal women also didn't benefit from misoprostol usage. ${ }^{18}$

Misoprostol can be administered oral, vaginal, sublingual, buccal or rectal for effective cervical dilatation and ripening. ${ }^{19}$ It is unclear that which route is effective for cervical dilatation before transvaginal procedures. However, vaginal misoprostol is similar to an extended release preparation due to its slower absorption, lower peak plasma levels and slower clearance and so that acts on cervix and uterus effectively for longer period. ${ }^{19}$ In the present study, we preferred to vaginal route as pharmaco-kinetic studies of misoprostol suggest more prolonged and sustained level of misoprostol with vaginal administration and found to be effective in terms of cervical ripening and reduction in pain. Similarly, Batukan et al, also claimed that vaginal administration was more effective than oral route of administration, whereas in another study no difference was observed between the two routes. ${ }^{20,21}$ In addition, on the contrary, Esteve $\mathrm{C}$ et al. stated that sublingual route is more effective than vaginal and oral routes. However, no specific studies were conducted to know the efficacy of sublingual administration of misoprostol in gynecological procedures. $^{22}$

A significant reduction in pain during dilatation for endometrial biopsy was observed in Group I patients as compared to Group II patients as evidenced by VAS score. About $38 \%$ of the patients in Group I have experienced no pain, $52 \%$ mild pain and $2 \%$ severe pain in the present study whereas in Group II, $48 \%$ of patients have suffered from severe pain and $40 \%$ of patients experienced mild pain suggesting the beneficial effects as well as efficacy of misoprostol on cervical ripening. But, on the contrary Perrona et al, stated that patients experienced more pain with oral $400 \mathrm{mcg}$ when given 3 hours prior to endometrial biopsy. ${ }^{20}$ However, the study had many pitfalls such as small sample size, inclusion of both premenopausal and postmenopausal women etc.

\section{CONCLUSION}

Vaginal administration of $400 \mathrm{mcg}$ misoprostol 4 hours prior to endometrial biopsy in premenopausal women had a significant effect on cervical resistance and cervical dilatation. Further studies are required in large number of populations to confirm the dosage and route of administration of misoprostol in endometrial biopsy.

Funding: No funding sources

Conflict of interest: None declared

Ethical approval: The study was approved by the Institutional Ethics Committee

\section{REFERENCES}

1. Bradley LD. Overview of hysteroscopy Version 17.2. Available at: http://www.uptodate.com. Accessed on $14^{\text {th }}$ September 2009.

2. Cooper JM, Erickson ML. Endometrial sampling techniques in the diagnosis of abnormal uterine bleeding. Obstet Gynecol Clin North Am. 2000;27:235-44.

3. Hofmeyr GJ, Gülmezoglu AM, Alfirevic Z. Misoprostol for induction of labour: A systematic review. Br J Obstet Gynaecol. 1999;106:798-803.

4. Cecatti JG, Tedesco RP, Pires HM, Calderon IM, Faúndes A. Effectiveness and safety of a new vaginal misoprostol product specifically labeled for cervical ripening and labor induction. Acta Obstet Gynecol Scand. 2006;85:706-11.

5. Sahu L, Chakravertty B. Comparison of prostaglandin E 1 (misoprostol) with prostaglandin E 2 (dinoprostone) for labor induction. J Obstet Gynecol India. 2004;54:139-42.

6. Sakhare AP, Mahale AR, Kardile GP. Vaginal misoprostol for medical evacuation of missed abortion. J Obstet Gynecol India. 2005;55:178-9.

7. Hamoda H, Ashok PW, Flett GM, Templeton A. A randomized controlled comparison of sublingual and vaginal administration of misoprostol for cervical priming before first-trimester surgical abortion. Am J Obstet Gynecol. 2004;190:55-9.

8. Blanchard K, Clark S, Winikoff B, Gaines G, Kabani G, Shannon C. Misoprostol for women's health: a review. Obstet Gynecol. 2002;99:316-32.

9. Carbonell JL, Velazco A, Rodriguez Y, Tanda R, Sanchez C, Barambio S, et al. Oral versus vaginal misoprostol for cervical priming in first-trimester abortion: a randomized trial. Eur $\mathrm{J}$ Contracept Reprod Health Care. 2001;6: 134-140.

10. MacIsaac L, Grossman D, Balistreri E, Darney P. A randomized controlled trial of laminaria, oral misoprostol, and vaginal misoprostol before abortion. Obstet Gynecol. 1999;93:766-70.

11. Tenore JL. Methods for cervical ripening and induction of labor. Am Fam Physician. 2003;67:2123-8.

12. Briggs GG, Wan SR. Drug therapy during labor and delivery, part 2. Am J Health Syst Pharm. 2006;63:1131-9.

13. Crane JM, Healey S. Use of misoprostol before hysteroscopy: a systematic review. J Obstet Gynaecol Can. 2006;28:373-9.

14. Oppegaard KS, Nesheim BI, Istre O, Qvigstad E. Comparison of self administered vaginal misoprostol 
versus placebo for cervical ripening prior to operative hysteroscopy using a sequential trial design. BJOG. 2008;115:663,e1-9.

15. Lee YY, Kim TJ, Kang H, Choi CH, Lee JW, Kim $\mathrm{BG}$, et al. The use of misoprostol before hysteroscopic surgery in non-pregnant premenopausal women: A randomized comparison of sublingual, oral and vaginal administrations. Hum Reprod. 2010;25:1942-8.

16. Dan Yu, Li TC, Xia E, Xiaowu H. A prospective randomized controlled trial comparing vaginal misoprostol and osmotic dilator in achieving cervical ripening before operative hysteroscopy. Gynecol Surg. 2006;3:186-9.

17. Perrone JF, Caldito G, Mailhes JB, Tucker AN, Ford WR, London SN. Oral misoprostol before office endometrial biopsy. Obstet Gynecol. 2002;99:43944.

18. Fung TM, Lam MH, Wong SF, Ho LC. A randomised placebo-controlled trial of vaginal misoprostol for cervical priming before hysteroscopy in postmenopausal women. BJOG. 2002;109:561-5.

19. Khan RU, El-Refaey H, Sharma S, Sooranna D, Stafford M. Oral, rectal, and vaginal pharmacokinetics of misoprostol. Obstet Gynecol. 2004;103:866-70.
20. Batukan C, Ozgun MT, Ozcelik B, Aygen E, Sahin Y, Turkyilmaz C. Cervical ripening before operative hysteroscopy in premenopausal women: a randomized, double-blind, placebo-controlled comparison of vaginal and oral misoprostol. Fertil Steril. 2008;89:966-73.

21. Choksuchat C, Cheewadhanaraks S, Getpook C, Wootipoom V, Dhanavoravibul K. Misoprostol for cervical ripening in non-pregnant women: a randomized double-blind controlled trial of oral versus vaginal regimens. Hum Reprod. 2006;21:2167-70.

22. Carbonell Esteve JL, Mari JM, Valero F, Llorente M, Salvador I, Varela L, et al. Sublingual versus vaginal misoprostol (400 microg) for cervical priming in first-trimester abortion: a randomized trial. Contracept. 2006;74:328-33.

Cite this article as: Prabhavathi V, Prasad DKV, Lahari N, Satyavathi R. Use of vaginal misoprostol before endometrial biopsy in premenopausal women: an observational study. Int J Reprod Contracept Obstet Gynecol 2020;9:2122-6. 